\title{
Evolving Trends in the Hepatitis C Virus Molecular Epidemiology Studies: From the Viral Sequences to the Human Genome
}

\author{
Julieta Trinks, ${ }^{1}$ Adrián Gadano, ${ }^{2}$ and Pablo Argibay ${ }^{1}$ \\ ${ }^{1}$ Instituto de Ciencias Básicas y Medicina Experimental (ICBME), Hospital Italiano de Buenos Aires, \\ C1181ACH Buenos Aires, Argentina \\ ${ }^{2}$ Unidad de Hepatología, Hospital Italiano de Buenos Aires, C1181ACH Buenos Aires, Argentina
}

Correspondence should be addressed to Julieta Trinks, julieta.trinks@hospitalitaliano.org.ar

Received 30 November 2011; Accepted 16 January 2012

Academic Editor: K. Matsuo

Copyright (C) 2012 Julieta Trinks et al. This is an open access article distributed under the Creative Commons Attribution License, which permits unrestricted use, distribution, and reproduction in any medium, provided the original work is properly cited.

\begin{abstract}
Hepatitis $\mathrm{C}$ virus (HCV) represents a major worldwide public health problem. The search for the key molecular biomarkers that may provide insight on the basis of the differences in disease progression, severity, and response to therapy is crucial for understanding the natural history of $\mathrm{HCV}$, for estimating the burden of infection and for developing preventive interventions. Initially, molecular epidemiology studies have focused on studying the viral genetic diversity (genotypes, genetic variants, specific nucleotide and amino acid substitutions). However, the clinical heterogeneities of HCV infection and the imperfect predictability of the response to treatment have suggested the need to search for host genetic biomarkers. This led to the discovery of genetic polymorphisms playing a major role in the evolution of infection, as well as in treatment response and adverse effects, such as $I L-28 B, I T P A$, and $I P-10$. As a consequence, nowadays the focus of molecular epidemiology studies has turned from the viral to the human genome. This paper will cover recent reports on the subject describing the most relevant viral as well as host genetic risk factors analyzed by past and current HCV molecular epidemiology studies.
\end{abstract}

\section{Introduction}

HCV represents a major health problem with approximately $3 \%$ of the world population-that is, more than 170 million people-infected. While only $20-30 \%$ of individuals exposed to HCV recover spontaneously, the remaining 70$80 \%$ develop chronic HCV infection (CHC) [1]. Moreover, $3-11 \%$ of those people will develop liver cirrhosis (LC) within 20 years [2], with associated risks of liver failure and hepatocellular carcinoma (HCC) [3] which are the leading indications of liver transplantation in industrialized countries [4]. The socioeconomic impact of HCV infection is therefore tremendous and the burden of the disease is expected to increase around the world as the disease progresses in patients who contracted HCV years ago.

Since the discovery of HCV more than 20 years ago [5], epidemiological studies have described complex patterns of infection concerning not only the worldwide prevalence of this virus but also its clinical presentation and its therapeutic response.
HCV presents highly variable local prevalence rates between countries and within countries [6]; for example, in Argentina the overall prevalence of $\mathrm{HCV}$ infection is close to $2 \%$, but higher rates have been reported in different small rural communities (5.7-4.9\%) [7, 8].

The outcome of HCV infection is-as previously stated-heterogeneous ranging from an asymptomatic selflimiting infection to LC and HCC. Recent studies have concluded that this difference appears to be dependent on the route of transmission and other host and viral related characteristics [9-12].

The current standard of care (SOC) for $\mathrm{CHC}$ is based on the combination of pegylated interferon-alfa (PEG-IFN) and ribavirin (RBV) for 24 or 48 weeks. A sustained virological response (SVR), defined by having undetectable serum HCV RNA 24 weeks after cessation of treatment, is associated with permanent cure in more than $99 \%$ of cases [13]. However, therapy is expensive and is associated with numerous side effects [14], which reduces its effectiveness in many cases (e.g., dialysis and HIV-infected patients, transplant 
recipients, etc.) [15], and sometimes requires dose reduction and premature treatment discontinuation, thus decreasing the rate of success. In addition to its limited efficacy, response to therapy is also variable and viral and host characteristics can influence whether patients achieve a SVR.

The search for the key molecular biomarkers that may provide insight on the basis of the differences in disease progression, severity, and response to therapy is crucial for understanding the natural history of $\mathrm{HCV}$, for estimating the burden of infection, and for developing preventive interventions.

In this regard, molecular epidemiology studies have first focused on identifying and measuring viral risk factors by analysis of HCV genetic diversity. As these failed to explain a large proportion of the variability, the existence of host genetic risk factors for HCV infection had been strongly suggested $[10,11]$. However, little progress could be made in their identification.

Recently, the completion of the Human Genome Project has led to the beginning of a new era of scientific research, including a revolutionary approach: the genome-wide association study (GWAS) which uses high-throughput genotyping technology usually for SNPs, ranging from 300,000 to 900,000 SNPs in each sample. Through these studies genetic factors strongly associated with disease susceptibility and drug response among $\mathrm{HCV}$-infected patients were finally detected [16]. As a consequence, nowadays the focus of molecular epidemiology studies has turned from the viral to the human genome.

The aim of this paper is to describe the most relevant viral as well as host genetic risk factors analyzed by past and current HCV molecular epidemiology studies.

\section{Molecular Epidemiology of HCV Genetic Diversity and Its Clinical and Therapeutic Implications}

Hepatitis C virus (HCV) is an enveloped RNA virus which contains a single-stranded, positive strand RNA molecule of approximately 9600 nucleotides [17]. Following the determination of the viral nucleotide and amino acid sequences [18], it was reported that different isolates of $\mathrm{HCV}$ as well as sequences isolated from each individual show substantial nucleotide sequence variation distributed throughout the genome $[19,20]$. The HCV genome contains both highly conserved and highly variable regions; for example, regions encoding the envelope proteins are the most variable, whereas the $5^{\prime}$ noncoding region (NCR) is the most conserved with minor heterogeneity [21]. For these reasons, several researchers have considered the $5^{\prime} \mathrm{NCR}$ to be the region of choice for viral detection.

Sequence analysis performed on isolates from different geographical areas around the world has revealed that it is possible to classify HCV into six different genotypes, labelled with numbers (1 to 6) [21]. Moreover, a seventh genotype was recently reported [22]. The degree of sequence variation between genotypes of HCV is similar to that observed between variants of other viruses, such as the serotypes of the flavivirus, dengue virus, or between poliovirus types 1,2 and, 3. HCV genotypes are further divided into multiple epidemiologically distinct subtypes-named with letters-due to the difference in the nucleotide sequence of the subgenomic regions such as core/E1 and NS5B (nonstructural 5B) [23].

Molecular epidemiological studies have shown that HCV genotypes display significant differences in their global distribution and prevalence. Genotypes 1, 2, and 3 are widely distributed throughout the USA, Europe, Australia, and East Asia (Japan, Taiwan, Thailand, and China), whereas geographical distributions of other genotypes are more restricted [24-26]. Genotype 4 is largely confined to the Middle East, Egypt, and Central Africa. Genotypes 5 and 6 prevail in South Africa and Southeast Asia, respectively $[24,25,27]$, and genotype 7 is found predominantly in central Africa [22]. Thus, genotyping has become a useful method to determine the source of HCV transmission in an infected localized population.

Many risk factors for disease progression and development of HCC have been reported, such as male gender, age at infection, diabetes, hepatic fibrosis (particularly cirrhosis), and greater degrees of hepatic inflammation, iron overload, steatosis, coinfection with HBV, alcohol abuse, smoking, and obesity [28-31]. On the basis of the observation that for most RNA viruses the existence of considerable sequence differences between serotypes has remarkably little effect on the phenotype of a virus, there would be no logical reason to suspect the existence of major differences between genotypes of HCV in their clinical course or disease associations. However, several cross-sectional studies-where the frequencies of infection with different genotypes are compared among patients with different disease outcomes-have concluded that HCV genotypes may be related to disease progression.

Although these studies have frequently produced contradictory results, it is generally agreed that genotype $1 \mathrm{~b}$ may be associated with more severe liver disease than infection with other genotypes [32-36]. There is also a greater consensus that infection with genotype $1 \mathrm{~b}$ predisposes towards the development of HCC [32, 35, 37-39], with only a few negative or contrary reports $[40,41]$. Regarding liver transplantation in HCV-infected patients, genotype $1 \mathrm{~b}$ is also associated with a higher rate of active disease after transplantation and graft destruction [42, 43].

Of the estimated 170 million HCV cases in the world, over 50\% occur among injection drug users (IDUs) [44]. Thus, IDUs are considered to be the main risk group for HCV infection and act as a reservoir for this bloodborne virus. Several reports have demonstrated a statistically significant relationship between HCV genotype 3, the injecting drug abuse, and a younger age of infection [45-49]. Moreover, by comparing patients infected with genotype 3 and those infected with other genotypes, numerous groups have revealed an association between this genotype and hepatic steatosis [50-55], and a severe histopathological manifestation of $\mathrm{CHC}$ which can improve after achieving SVR with the antiviral treatment [56-58].

In addition to their clinical importance as predictors of disease progression, HCV genotypes also offer essential 
information to those providing or receiving treatment. Present data strongly indicate that HCV genotype is the key determinant of response to IFN-alpha-based treatment regimens [59-62].

The actual SOC therapy, in a patient with hepatitis C, yields a sustained response in approximately $55 \%$ of the cases. Patients with genotypes 1 and 4 generally exhibit a poorer response to IFN-based therapy than those with genotypes 2 and 3, probably due to slower viral kinetics [63]. HCV genotype 5 appears to be an easily treatable virus, with response rates compatible with those of genotypes 2 and 3 after a 48-week course of therapy [61, 62]. Treatment response in genotype $6 \mathrm{HCV}$ patients may be at an intermediate level between that observed in genotype 1 and genotypes 2 and 3 .

In patients with HCV genotypes 2 or 3, the SVR rates reach $80-95 \%$, while with genotype 1, patients achieve SVR rates in only $54-65 \%$ of the cases [64-68]. Finally, response rates for genotype 4 are higher than those for genotype 1, but lower than those for genotype 3 (approximately 65\%).

Interestingly, several studies have demonstrated that the chance to respond to IFN treatment is also related to the baseline viral load. While patients with a high viral load $(>800000 \mathrm{UI} / \mathrm{mL})$ are less sensitive to the treatment, patients with a low viral load $(<800000 \mathrm{UI} / \mathrm{mL})$ respond better to therapy [69]. Thus, patients with genotype 1, low baseline viral load, and rapid virological response (HCV RNA negative in serum after 4 weeks of treatment) may be treated for 24 weeks, while patients with genotype 3, high baseline viral load, and without rapid virological response may require 48 weeks of treatment.

Interestingly, during its replication, HCV has the particularity to generate genetic variants, which exhibit $10 \%$ of nucleotide divergence among them. Thus, sensitivity to HCV therapy can be variable due to the emergence of variants with mutations that confer a different sensibility to the treatment.

In this regard, specific nucleotide and amino acid substitutions in the viral genome have been reported to be correlated with the effect of both IFN therapy and PEGIFN plus ribavirin combination therapy. Two amino acid regions of NS5A have been described and are thought to play a role in response to IFN treatment: (1) IFN sensitivitydetermining region (ISDR) $[70,71]$ and (2) IFN/RBV resistance-determining region (IRRDR) [72]. The outcome of IFN therapy is related to the total number of amino acid substitutions in these regions. Recently, others mutationswithin core (amino acid 70 and 91), E2 (PePHD), NS5A (PKRBD and variable region 3)- have been implicated in influencing the response to IFN therapy in patients infected with genotype 1 of HCV [73-76].

\section{Molecular Epidemiology of HCV-Related Single-Nucleotide Polymorphisms (SNPs) in the Human Genome and Their Clinical and Therapeutic Implications}

After the beginning of the genomic era, studies of human genetics have been expected to alter clinical management for many diseases, including infectious diseases. Yet, to date, there are few examples of the use of such information in routine clinical practice. One of the most promising examples is the case of HCV.

Responsiveness to HCV therapy depends not only on viral factors but also on host factors. Older age, male sex, cirrhosis, steatosis, insulin resistance, diabetes, African American ethnicity, and weight (BMI) are all events associated to poor response to PEG-IFN plus RBV treatment $[77,78]$. Comorbidities such as HIV and/or HBV coinfection, excess alcohol intake, and drug use are generally associated with lower SVR rates [79]. It seems that cannabis receptor stimulation is associated with lower response to IFN treatment [80]. Moreover, it has been recently reported that patients with a history of depression who were not receiving antidepressants and active intravenous drug users are more likely to fail treatment for HCV genotype 2 or 3 and will need additional support [81].

Initially, candidate gene approaches had been adopted to identify host factors related to HCV therapy response, SNPs, copy number variation $(\mathrm{CNV})$, or insertion/deletion of genes [82-84]. However, these approaches could latently find weak associations and show significant differences because only one or a limited number of SNPs or gene loci are detected in candidate genes.

In 2009-2010, on the basis of the GWAS, four independent groups assessed the role of genetic variation on response to PEG-IFN plus RBV combination therapy for CHC patients infected with genotype 1 [85-88]. Although different ethnicities (European, African American, Hispanic, Australian, and Japanese) have been compared in these studies, the conclusive finding was-in all cases-that polymorphisms in or near the $I L-28 B$ gene, also known as IFN$3 \lambda$, on chromosome 19 strongly determined the outcome of HCV therapy.

Ge et al. identified a genetic polymorphism (rs12979860) in the $I L-28 B$ gene [86]. Individuals with the CC genotype showed the significant association with an approximately twofold change in response to PEG-IFN plus RBV treatment compared with those with the TT genotype, both among patients of European ancestry and African Americans. An important finding in this study is the strong correlation between being a carrier of this SNP and SVR rates in diverse ethnic groups, which is significantly more frequent in European (53-85\%) and Asian populations (90\%) than in African-Americans (23-55\%). This SNP could finally explain much of the recognized ethnic disparity between African Americans and Europeans in treatment response rates.

On the other hand, Suppiah et al. and Tanaka et al. revealed the strong association of particular haplotypes of SNP rs8099917 (8 kb upstream of $I L-28 B$ ) with SVR in the European and Japanese population infected with HCV genotype 1 and treated with PEG-IFN plus RBV therapy $[85,87]$. Homozygotes for the risk allele (rs8099917 G-allele) showed 2 -fold higher risk of treatment failure than that of major allele homozygotes.

In the fourth GWAS that was published on the response to HCV therapy, Rauch et al. studied Swiss patients infected with HCV genotype $1,2,3$, or 4 [88]. The strongest 
association with treatment failure was also found with rs8099917. Interestingly, this SNP was not associated with the response to PEG-IFN plus RBV therapy in genotype 2 or 3 patients. The contribution of host factors to genotype 2 or 3 clearance would be low because HCV genotype 2 or 3 is likely to be eliminated by the standard therapy compared with genotype 1 .

In contrast, Kawaoka et al. revealed that for Japanese patients treated with PEG-IFN plus RBV, rs8099917, and viral load were independent predictive factors for SVR in genotype $2 \mathrm{~b}$ but not in genotype $2 \mathrm{a}$. Conversely, in patients treated with interferon monotherapy, viral load and rs8099917 were independent predictive factors for SVR in genotype $2 \mathrm{a}$ but not in genotype 2b [89]. Moreover, Sarrazin et al. reported a significant association of the CC genotype of rs12979860 with SVR in European patients infected with HCV genotypes 2 and 3 [90].

For HCV-infected patients with end-stage chronic liver disease, orthotopic liver transplantation (OLT) is currently the treatment of choice [91]. Several reports have shown that post-OLT patient and graft survival are significantly negatively affected by HCV recurrence after OLT [92, 93]. This can be mitigated by achievement of an SVR with PEGIFN plus RBV therapy [94]. However, many patients cannot tolerate curative doses or do not respond to therapy [93-95]. Therefore, as it would be ideal to be able to predict which patients would benefit from PEG-IFN plus RBV therapy for recurrent $\mathrm{HCV}$, it was recently reported that variants of the SNPs in or around the $I L-28 B$ gene from liver donors are also strongly associated to the degree of graft inflammation and the response to therapy of $\mathrm{HCV}$-infected liver recipients [9698].

In addition to $I L-28 B$ SNPs, other host molecular predictors of response to PEG-IFN plus RBV therapy have been documented. Human leukocyte antigen (HLA) and killer cell immunoglobulin-like receptors (KIRs) are highly polymorphic genetic loci whose gene proteins interact with each other. HLA-C molecules present ligands for KIR2DL receptors, with a functionally relevant dimorphism determining KIR specificity: for example, HLA-C group 1 (HLAC1) alleles, identified by Ser77/Asp80 of the HLA-C alpha 1 domain, are ligands for the inhibitory receptors KIR2DL2 and KIR2DL3 and the activating receptor KIR2DS2 [99, 100]. KIR2DL3 and its ligand, HLA-C1, have been associated with an increased likelihood of spontaneous [101-103] and treatment-induced HCV clearance $[102,103]$. This association is attributed to differential natural killer (NK) cell activation and function in the context of this KIR/HLA interaction [104]. In a recent cross-sectional study, Suppiah et al. concluded that IL28-B, HLA-C, and KIR variants additively predict response to therapy in $\mathrm{CHC}$ European patients [105].

Furthermore, interferon-gamma inducible protein $10 \mathrm{kDa}$ (IP-10 or CXCL10) is a chemotactic CXC chemokine produced by a variety of cells, including hepatocytes $[106,107]$. IP-10 targets the CXCR3 receptor and attracts T lymphocytes, NK cells, and monocytes to sites of infection [107-109]. Levels of IP-10 at onset of therapy are reportedly elevated in patients infected with HCV of genotypes 1 or 4 who do not achieve SVR [110]. In difficult-to-treat genotype1-infected HCV patients, cut-off levels of IP-10 in plasma of $150 \mathrm{pg} / \mathrm{mL}$ (approximately equal to 2 standard deviations above the mean IP-10 level of HCV seronegative blood donors) and $600 \mathrm{pg} / \mathrm{mL}$ have yielded positive and negative predictive values for SVR of $71 \%$ and $100 \%$, respectively [111]. IP-10 in plasma is mirrored by intrahepatic IP-10 mRNA and strongly predicts the HCV RNA decline during the first days ("first phase decline") during IFN/RBV therapy for all HCV genotypes [112]. According to recent reports, the assessment of both pretreatment IP-10 and IL28-B SNPS augments the prediction of the first phase decline in HCV RNA and, therefore, final therapeutic outcome $[113,114]$.

As previously stated, in addition to its limited efficacy, SOC therapy is expensive and is associated with numerous side effects. In particular, anemia is a very common adverse effect of HCV combination treatment caused by RBVinduced hemolysis and IFN-related bone marrow toxicity. RBV-induced hemolytic anemia (HA) is usually reversible and dose related $[115,116]$, but may require significant dose reductions possibly affecting efficacy, and is a cause of withdrawal from therapy in $10-14 \%$ of patients [64, 117-120]. Several risk factors for RBV-induced HA have been identified, for example, age, female gender, dose and plasma concentration of RBV, baseline hemoglobin and platelets, and haptoglobin phenotype [121-124]. However, the severity of RBV-induced HA shows great variability among individuals, suggesting that the genetic background may exert a profound influence on the clinical expression of this adverse effect.

With the aim to detect predictor biomarkers that could evaluate possible risks over benefits from currently available treatment and thus avoid these side effects in patients who will not be helped by the treatment, as well as reduce the substantial cost of the treatment, recent studies indicated that genetic variants leading to inosine triphosphatase (ITPase) deficiency, a benign red cell enzymopathy [125], protect against hemolytic anemia in $\mathrm{CHC}$ patients receiving $\mathrm{RBV}$. In an American GWAS, a strong association was shown between hemoglobin reduction after 4 weeks of treatment and SNP rs6051702 [126]. The association was explained by two known functional variants in the ITPA gene, located on chromosome 20 and encoding for inosine triphosphatase (ITPase). The two variants, a missense polymorphism in exon 2 (g.3141842C>A, P32T; rs1127354) and a splicealtering SNP located in the second intron (g.8838A $>$ C, rs7270101), result in reduced enzyme activity: homozygosity for the P32T mutation leads to undetectable ITPase activity, accumulation of its substrate ITP in erythrocytes, and increased toxicity of purine analogue drugs [125, 127-131]. Conversely, reduced ITPase activity may be protective from RBV-induced hemolysis through the competition of ITP with RBV-TP [127, 132].

The same results obtained by Fellay et al. [126] were reported by Thompson et al. [133], who documented as well a strong association between ITPase deficiency and lower frequency of RBV-induced HA over the complete 48-week therapeutic course for patients infected with HCV genotype 1. Of note, ITPA variants did not affect treatment response. 
Recent results by the same group analyzed patients infected with HCV genotypes 2 and 3, showing that ITPA variants are protective against treatment-related anemia, but are not related to the rate of SVR [134]. Among Japanese patients, only the SNP rs1127354 was strongly associated with the incidence and severity of RBV-induced HA $[135,136]$.

In addition to their role as predictors of PEG-IFN plus treatment response, the SNPs in or around the $I L$ $28 \mathrm{~B}$ gene are also associated with spontaneous clearance of HCV infection. Thomas et al. reported a strong association of rs12979860 with spontaneous recovery found in HCVinfected European and African American individuals [137]. This association was independent of coinfection with HIV, type of HCV transmission, and history of HBV infection. Moreover, Rauch et al. revealed the host factor associated with spontaneous clearance of HCV was rs8099917, independently of HIV coinfection [88].

As in HCV infection an inappropriate ratio of proinflammatory and anti-inflammatory cytokines may determine the different outcomes of the infection (viral clearance or persistence), polymorphisms in regulatory regions of cytokine genes were studied. As a consequence, it was recently reported that genetic polymorphisms in the promoter region of interleukin-10 (IL-10) are possible predictors of not only the spontaneous favourable outcome of HCV infection but also of the progression of liver fibrosis $[138,139]$.

Of note, the relationship between different levels of hepatic steatosis in patients infected with genotype 3 and host genetic SNPs was identified, suggesting that a small difference in host genetic factors may result in different outcomes of the disease with the same pathogen. Zampino et al. revealed that the presence of $\mathrm{T}$ allele in the $-493 \mathrm{G} / \mathrm{T}$ polymorphism of microsomal triglyceride transfer protein $(M T P)$ gene reduces the activity of this key enzyme of assembly/secretion of lipoproteins and predisposes patients infected with HCV genotype 3 to develop higher degree of fatty liver accumulation [140]. Moreover, the SNP rs738409 of adiponutrin/patatin-like phospholipase domain-containing 3 (PNPLA3), which encodes for the I148M protein variant, has been recognized as a determinant of liver fat content. In HCV infection, it also influences steatosis development and is independently associated with cirrhosis and other steatosis-related clinical outcomes, such as lack of response to antiviral treatment and possibly HCC [141].

\section{Future Perspectives}

Over the past few years, a great progress has been made in understanding the heterogeneous disease progression and treatment response in HCV infection. In the clinical practice, physicians will soon be able to offer to infected patients a tailor-made medicine by combining the screening of both viral and host molecular biomarkers.

The unprecedented increase in the spread of HCV documented during the 20th century has resulted in the wave of increased HCV-related morbidity and mortality that we are now facing. Moreover, over the next 10 years the incidence of complications of $\mathrm{CHC}$ will not decline because most patients remain undiagnosed.

Decisions on public health issues such as HCV screening, prevention measures, and early treatment have the potential to reduce the overall morbidity and mortality. However, these depend on reliable epidemiological data, which is still scarce.

Therefore, local and/or regional molecular epidemiology studies concerning the viral and the newly reported hostrelated aspects of infection are urgently needed.

\section{References}

[1] H. S. Te and D. M. Jensen, "Epidemiology of hepatitis B and C viruses: a global overview," Clinics in Liver Disease, vol. 14, no. 1, pp. 1-21, 2010.

[2] G. J. Dore, A. J. Freeman, M. Law, and J. M. Kaldor, "Is severe liver disease a common outcome for people with chronic hepatitis C?" Journal of Gastroenterology and Hepatology, vol. 17, no. 4, pp. 423-430, 2002.

[3] T. Poynard, M. F. Yuen, V. Ratziu, and C. L. Lai, "Viral hepatitis C," The Lancet, vol. 362, no. 9401, pp. 2095-2100, 2003.

[4] N. Muhlberger, R. Schwarzer, B. Lettmeier, G. Sroczynski, S. Zeuzem, and U. Siebert, "HCV-related burden of disease in Europe: a systematic assessment of incidence, prevalence, morbidity, and mortality," BMC Public Health, vol. 9, article 34, 2009.

[5] Q. L. Choo, G. Kuo, A. J. Weiner, L. R. Overby, D. W. Bradley, and M. Houghton, "Isolation of a cDNA clone derived from a blood-borne non-A, non-B viral hepatitis genome," Science, vol. 244, no. 4902, pp. 359-362, 1989.

[6] D. Lavanchy, "Evolving epidemiology of hepatitis C virus," Clinical Microbiology and Infection, vol. 17, no. 2, pp. 107115, 2011.

[7] G. R. Picchio, P. C. Baré, V. I. Descalzi et al., "High prevalence of infection with a single hepatitis $C$ virus genotype in a small rural community of Argentina," Liver International, vol. 26, no. 6, pp. 660-665, 2006.

[8] M. D. Golemba, F. A. Di Lello, F. Bessone et al., "High prevalence of hepatitis $C$ virus genotype $1 \mathrm{~b}$ infection in a small town of Argentina. Phylogenetic and Bayesian coalescent analysis," PLoS One, vol. 5, no. 1, Article ID e8751, 2010.

[9] J. Crebely, J. D. Raffa, C. Lai, M. Krajden, B. Conway, and M. W. Tyndall, "Factors associated with spontaneous clearance of hepatitis C virus among illicit drug users," Canadian Journal of Gastroenterology, vol. 21, no. 7, pp. 447-451, 2007.

[10] D. L. Thomas, J. Astemborski, R. M. Rai et al., "The natural history of hepatitis $\mathrm{C}$ virus infection: host, viral, and environmental factors," Journal of the American Medical Association, vol. 284, no. 4, pp. 450-456, 2000.

[11] K. B. Aborsangaya, I. Dembinski, S. Khatkar, M. P. Alphonse, P. Nickerson, and J. D. Rempel, "Impact of aboriginal ethnicity on HCV core-induced IL-10 synthesis: interaction with IL-10 gene polymorphisms," Hepatology, vol. 45, no. 3, pp. 623-630, 2007.

[12] M. P. Busch, S. A. Glynn, S. L. Stramer et al., "Correlates of hepatitis C virus (HCV) RNA negativity among HCVseropositive blood donors," Transfusion, vol. 46, no. 3, pp. 469-475, 2006. 
[13] M. G. Swain, M. I. Lai, M. L. Shiffman et al., "A sustained virologic response is durable in patients with chronic hepatitis C treated with peginterferon alfa-2a and ribavirin," Gastroenterology, vol. 139, no. 5, pp. 1593-1601, 2010.

[14] E. Bjornsson, H. Verbaan, A. Oksanen et al., "Healthrelated quality of life in patients with different stages of liver disease induced by hepatitis C," Scandinavian Journal of Gastroenterology, vol. 44, no. 7, pp. 878-887, 2009.

[15] NIH, "National institutes of health consensus development conference statement: management of hepatitis C 2002 (2002 Jun 10-12)," Gastroenterology, vol. 123, no. 6, pp. 2082-2099, 2002.

[16] M. Thursz, L. Yee, and S. Khakoo, "Understanding the host genetics of chronic hepatitis B and C," Seminars in Liver Disease, vol. 31, no. 2, pp. 115-127, 2011.

[17] T. Suzuki, H. Aizaki, K. Murakami, I. Shoji, and T. Wakita, "Molecular biology of hepatitis C virus," Journal of Gastroenterology, vol. 42, no. 6, pp. 411-423, 2007.

[18] N. Kato, M. Hijikata, Y. Ootsuyama et al., "Molecular-cloning of the human hepatitis- $\mathrm{C}$ virus genome from Japanese patients with non-A, non- $\mathrm{B}$ hepatitis," Proceedings of the National Academy of Sciences of the United States of America, vol. 87, no. 24, pp. 9524-9528, 1990.

[19] N. Kato, M. Hijikata, Y. Ootsuyama, M. Nakagawa, S. Ohkoshi, and K. Shimotohno, "Sequence diversity of hepatitis C viral genomes," Molecular Biology and Medicine, vol. 7, no. 6, pp. 495-501, 1990.

[20] Q. L. Choo, K. H. Richman, J. H. Han et al., "Genetic organization and diversity of the hepatitis C virus," Proceedings of the National Academy of Sciences of the United States of America, vol. 88, no. 6, pp. 2451-2455, 1991.

[21] P. Simmonds, E. C. Holmes, T. A. Cha et al., "Classification of hepatitis $\mathrm{C}$ virus into six major genotypes and a series of subtypes by phylogenetic analysis of the NS-5 region," Journal of General Virology, vol. 74, no. 11, pp. 2391-2399, 1993.

[22] D. Murphy, J. Chamberland, R. Dandavino, and E. Sablon, "A new genotype of hepatitis $\mathrm{C}$ virus originating from central Africa," Hepatology, vol. 46, supplement 1, article 623a, 2007.

[23] P. Simmonds, J. Bukh, C. Combet et al., "Consensus proposals for a unified system of nomenclature of hepatitis $\mathrm{C}$ virus genotypes," Hepatology, vol. 42, no. 4, pp. 962-973, 2005.

[24] P. Simmonds, "Clinical relevance of hepatitis C virus genotypes," Gut, vol. 40, no. 3, pp. 291-293, 1997.

[25] F. McOmish, P. L. Yap, B. C. Dow et al., "Geographical distribution of hepatitis $\mathrm{C}$ virus genotypes in blood donors: an international collaborative survey," Journal of Clinical Microbiology, vol. 32, no. 4, pp. 884-892, 1994.

[26] J. H. Kao, P. J. Chen, M. Y. Lai et al., "Genotypes of hepatitis C virus in Taiwan and the progression of liver disease," Journal of Clinical Gastroenterology, vol. 21, no. 3, pp. 233-237, 1995.

[27] S. Agha, Y. Tanaka, N. Saudy et al., "Reliability of hepatitis $\mathrm{C}$ virus core antigen assay for detection of viremia in $\mathrm{HCV}$ genotypes 1, 2, 3, and 4 infected blood donors: a collaborative study between Japan, Egypt, and Uzbekistan," Journal of Medical Virology, vol. 73, no. 2, pp. 216-222, 2004.

[28] M. M. Hassan, L. Y. Hwang, C. J. Hatten et al., "Risk factors for hepatocellular carcinoma: synergism of alcohol with viral hepatitis and diabetes mellitus," Hepatology, vol. 36, no. 5, pp. 1206-1213, 2002.

[29] G. Fattovich, T. Stroffolini, I. Zagni, and F. Donato, "Hepatocellular carcinoma in cirrhosis: incidence and risk factors," Gastroenterology, vol. 127, supplement 1, no. 5, pp. S35-S50, 2004.
[30] A. Kasahara, N. Hayashi, K. Mochizuki et al., "Risk factors for hepatocellular carcinoma and its incidence after interferon treatment in patients with chronic hepatitis C," Hepatology, vol. 27, no. 5, pp. 1394-1402, 1998.

[31] C. H. Hung, C. M. Lee, S. N. Lu et al., "Long-term effect of interferon alpha-2b plus ribavirin therapy on incidence of hepatocellular carcinoma in patients with hepatitis $\mathrm{C}$ virusrelated cirrhosis," Journal of Viral Hepatitis, vol. 13, no. 6, pp. 409-414, 2006.

[32] C. H. Chen, J. C. Sheu, J. T. Wang et al., "Genotypes of hepatitis C virus in chronic liver disease in Taiwan," Journal of Medical Virology, vol. 44, no. 3, pp. 234-236, 1994.

[33] J. C. L. Booth, G. R. Foster, U. Kumar et al., "Chronic hepatitis $\mathrm{C}$ virus infections: predictive value of genotype and level of viraemia on disease progression and response to interferon alpha," Gut, vol. 36, no. 3, pp. 427-432, 1995.

[34] M. Kobayashi, E. Tanaka, T. Sodeyama, A. Urushihara, A. Matsumoto, and K. Kiyosawa, "The natural course of chronic hepatitis C: a comparison between patients with genotypes 1 and 2 hepatitis C viruses," Hepatology, vol. 23, no. 4, pp. 695699, 1996.

[35] A. Takada, M. Tsutsumi, S. C. Zhang et al., "Relationship between hepatocellular carcinoma and subtypes of hepatitis C virus: a nationwide analysis," Journal of Gastroenterology and Hepatology, vol. 11, no. 2, pp. 166-169, 1996.

[36] K. Ikeda, M. Kobayashi, T. Someya et al., "Influence of hepatitis $\mathrm{C}$ virus subtype on hepatocellular carcinogenesis: a multivariate analysis of a retrospective cohort of 593 patients with cirrhosis," Intervirology, vol. 45, no. 2, pp. 71-78, 2002.

[37] M. Yamauchi, M. Nakahara, H. Nakajima, K. Sakamoto, J. Hirakawa, and G. Toda, "Different prevalence of hepatocellular carcinoma between patients with liver cirrhosis due to genotype II and III of hepatitis C virus," International Hepatology Communications, vol. 2, no. 6, pp. 328-332, 1994.

[38] G. H. Haydon, L. M. Jarvis, P. Simmonds, and P. C. Hayes, "Association between chronic hepatitis C infection and hepatocellular carcinoma," The Lancet, vol. 345, no. 8954, pp. 928-929, 1995.

[39] K. Tanaka, H. Ikematsu, T. Hirohata, and S. Kashiwagi, "Hepatitis C virus infection and risk of hepatocellular carcinoma among Japanese: possible role of type $1 \mathrm{~b}$ (II) infection," Journal of the National Cancer Institute, vol. 88, no. 11, pp. 742-746, 1996.

[40] H. Yotsuyanagi, K. Koike, K. Yasuda et al., "Hepatitis C virus genotypes and development of hepatocellular carcinoma," Cancer, vol. 76, no. 8, pp. 1352-1355, 1995.

[41] D. S. Lee, Y. C. Sung, and Y. S. Whang, "Distribution of HCV genotypes among blood donors, patients with chronic liver disease, hepatocellular carcinoma, and patients on maintenance hemodialysis in Korea," Journal of Medical Virology, vol. 49, no. 1, pp. 55-60, 1996.

[42] E. J. Gane, N. V. Naoumov, K. P. Qian et al., "A longitudinal analysis of hepatitis $\mathrm{C}$ virus replication following liver transplantation," Gastroenterology, vol. 110, no. 1, pp. 167177, 1996.

[43] E. J. Gane, B. C. Portmann, N. V. Naoumov et al., "Long-term outcome of hepatitis C infection after liver transplantation," New England Journal of Medicine, vol. 334, no. 13, pp. 815820, 1996.

[44] C. W. Shepard, L. Finelli, and M. J. Alter, "Global epidemiology of hepatitis C virus infection," The Lancet Infectious Diseases, vol. 5, no. 9, pp. 558-567, 2005.

[45] F. McOmish, S. W. Chan, B. C. Dow et al., "Detection of three types of hepatitis $\mathrm{C}$ virus in blood donors: investigation 
of type-specific differences in serologic reactivity and rate of alanine aminotransferase abnormalities," Transfusion, vol. 33, no. 1, pp. 7-13, 1993.

[46] J. M. Pawlotsky, L. Tsakiris, F. Roudot-Thoraval et al., "Relationship between hepatitis C virus genotypes and sources of infection in patients with chronic hepatitis C," Journal of Infectious Diseases, vol. 171, no. 6, pp. 1607-1610, 1995.

[47] S. G. Tisminetzky, M. Gerotto, P. Pontisso et al., "Genotypes of hepatitis $\mathrm{C}$ virus in Italian patients with chronic hepatitis C," International Hepatology Communications, vol. 2, no. 2, pp. 105-112, 1994.

[48] J. Y. N. Lau, G. L. Davis, L. E. Prescott et al., "Distribution of hepatitis $\mathrm{C}$ virus genotypes determined by line probe assay in patients with chronic hepatitis $\mathrm{C}$ seen at tertiary referral centers in the United States," Annals of Internal Medicine, vol. 124, no. 10, pp. 868-876, 1996.

[49] P. Simmonds, J. Mellor, A. Craxi et al., "Epidemiological, clinical and therapeutic associations of hepatitis C types in western European patients," Journal of Hepatology, vol. 24, no. 5, pp. 517-524, 1996.

[50] S. Mihm, A. Fayyazi, H. Hartmann, and G. Ramadori, "Analysis of histopathological manifestations of chronic hepatitis C virus infection with respect to virus genotype," Hepatology, vol. 25, no. 3, pp. 735-739, 1997.

[51] L. Rubbia-Brandt, R. Quadri, K. Abid et al., "Hepatocyte steatosis is a cytopathic effect of hepatitis $\mathrm{C}$ virus genotype 3," Journal of Hepatology, vol. 33, no. 1, pp. 106-115, 2000.

[52] L. Rubbia-Brandt, G. Leandro, L. Spahr et al., "Liver steatosis in chronic hepatitis C: a morphological sign suggesting infection with HCV genotype 3," Histopathology, vol. 39, no. 2, pp. 119-124, 2001.

[53] P. Sharma, V. Balan, J. Hernandez et al., "Hepatic steatosis in hepatitis $\mathrm{C}$ virus genotype 3 infection: does it correlate with body mass index, fibrosis, and HCV risk factors?" Digestive Diseases and Sciences, vol. 49, no. 1, pp. 25-29, 2004.

[54] F. D. Gordon, E. A. Pomfret, J. J. Pomposelli, W. D. Lewis, R. L. Jenkins, and U. Khettry, "Severe steatosis as the initial histologic manifestation of recurrent hepatitis C genotype 3," Human Pathology, vol. 35, no. 5, pp. 636-638, 2004.

[55] S. S. Hissar, A. Goyal, M. Kumar et al., "Hepatitis C virus genotype 3 predominates in north and central India and is associated with significant histopathologic liver disease," Journal of Medical Virology, vol. 78, no. 4, pp. 452-458, 2006.

[56] D. Kumar, G. C. Farrell, C. Fung, and J. George, "Hepatitis C virus genotype 3 is cytopathic to hepatocytes: reversal of hepatic steatosis after sustained therapeutic response," Hepatology, vol. 36, no. 5, pp. 1266-1272, 2002.

[57] J. Westin, H. Nordlinder, M. Lagging, G. Norkrans, and R. Wejstal, "Steatosis accelerates fibrosis development over time in hepatitis C virus genotype 3 infected patients," Journal of Hepatology, vol. 37, no. 6, pp. 837-842, 2002.

[58] L. Castera, C. Hezode, F. Roudot-Thoraval et al., "Effect of antiviral treatment on evolution of liver steatosis in patients with chronic hepatitis C: indirect evidence of a role of hepatitis C virus genotype 3 in steatosis," Gut, vol. 53, no. 3, pp. 420-424, 2004.

[59] Y. Shiratori, N. Kato, O. Yokosuka et al., "Predictors of the efficacy of interferon therapy in chronic hepatitis $\mathrm{C}$ virus infection," Gastroenterology, vol. 113, no. 2, pp. 558-566, 1997.

[60] N. N. Zein, J. Rakela, E. L. Krawitt, K. R. Reddy, T. Tominaga, and D. H. Persing, "Hepatitis C virus genotypes in the United States: epidemiology, pathogenicity, and response to interferon therapy," Annals of Internal Medicine, vol. 125, no. 8, pp. 634-639, 1996.

[61] M. H. Nguyen and E. B. Keeffe, "Prevalence and treatment of hepatitis C virus genotypes 4, 5, and 6," Clinical Gastroenterology and Hepatology, vol. 3, supplement 2, no. 10, pp. S97-S101, 2005.

[62] H. J. Hnatyszyn, "Chronic hepatitis C and genotyping: the clinical significance of determining HCV genotypes," Antiviral Therapy, vol. 10, no. 1, pp. 1-11, 2005.

[63] P. Halfon, A. U. Neumann, M. Bourliere et al., "Slow viral dynamics of hepatitis C virus genotype 4," Journal of Viral Hepatitis, vol. 10, no. 5, pp. 351-353, 2003.

[64] M. W. Fried, M. L. Shiffman, K. R. Reddy et al., "Peginterferon alfa-2a plus ribavirin for chronic hepatitis $\mathrm{C}$ virus infection," New England Journal of Medicine, vol. 347, no. 13, pp. 975-982, 2002.

[65] S. J. Hadziyannis, H. Sette Jr, T. R. Morgan et al., "Peginterferon-alpha2a and ribavirin combination therapy in chronic hepatitis C: a randomized study of treatment duration and ribavirin dose," Annals of Internal Medicine, vol. 140, no. 5, pp. 346-355, 2004.

[66] A. Mangia, R. Santoro, N. Minerva et al., "Peginterferon alfa$2 \mathrm{~b}$ and ribavirin for 12 vs. 24 weeks in HCV genotype 2 or 3," New England Journal of Medicine, vol. 352, no. 25, pp. 26092617, 2005.

[67] M. L. Yu, C. Y. Dai, J. F. Huang et al., "A randomised study of peginterferon and ribavirin for 16 vs 24 weeks in patients with genotype 2 chronic hepatitis C," Gut, vol. 56, no. 4, pp. 553-559, 2007.

[68] S. D. Lee, M. L. Yu, P. N. Cheng et al., "Comparison of a 6-month course peginterferon alpha-2b plus ribavirin and interferon alpha-2b plus ribavirin in treating Chinese patients with chronic hepatitis C in Taiwan," Journal of Viral Hepatitis, vol. 12, no. 3, pp. 283-291, 2005.

[69] T. Berg, C. Sarrazin, E. Herrmann et al., "Prediction of treatment outcome in patients with chronic hepatitis C: significance of baseline parameters and viral dynamics during therapy," Hepatology, vol. 37, no. 3, pp. 600-609, 2003.

[70] S. Zeuzem, J. H. Lee, and W. K. Roth, "Mutations in the nonstructural 5A gene of European hepatitis $\mathrm{C}$ virus isolates and response to interferon alfa," Hepatology, vol. 25, no. 3, pp. 740-744, 1997.

[71] N. Enomoto, I. Sakuma, Y. Asahina et al., "Mutations in the nonstructural protein $5 \mathrm{~A}$ gene and response to interferon in patients with chronic hepatitis C virus $1 \mathrm{~b}$ infection," New England Journal of Medicine, vol. 334, no. 2, pp. 77-81, 1996.

[72] A. El-Shamy, M. Nagano-Fujii, N. Sasase, S. Imoto, S. R. Kim, and H. Hotta, "Sequence variation in hepatitis $\mathrm{C}$ virus nonstructural protein $5 \mathrm{~A}$ predicts clinical outcome of pegylated interferon/ribavirin combination therapy," Hepatology, vol. 48, no. 1, pp. 38-47, 2008.

[73] N. Enomoto and S. Maekawa, "HCV genetic elements determining the early response to peginterferon and ribavirin therapy," Intervirology, vol. 53, no. 1, pp. 66-69, 2010.

[74] P. Munoz de Rueda, J. Casado, R. Paton et al., "Mutations in E2-PePHD, NS5A-PKRBD, NS5A-ISDR, and NS5A-V3 of hepatitis $\mathrm{C}$ virus genotype 1 and their relationships to pegylated interferon-ribavirin treatment responses," Journal of Virology, vol. 82, no. 13, pp. 6644-6653, 2008.

[75] T. Berg, A. M. Marques, M. Hohne, B. Wiedenmann, U. Hopf, and E. Schreier, "Mutations in the E2-PePHD and NS5A region of hepatitis $C$ virus type 1 and the dynamics of hepatitis C viremia decline during interferon alfa treatment," Hepatology, vol. 32, no. 6, pp. 1386-1395, 2000. 
[76] N. Akuta, F. Suzuki, Y. Kawamura et al., "Predictors of viral kinetics to peginterferon plus ribavirin combination therapy in Japanese patients infected with hepatitis $\mathrm{C}$ virus genotype 1b," Journal of Medical Virology, vol. 79, no. 11, pp. 16861695, 2007.

[77] T. Asselah, L. Rubbia-Brandt, P. Marcellin, and F. Negro, "Steatosis in chronic hepatitis C: why does it really matter?" Gut, vol. 55, no. 1, pp. 123-130, 2006.

[78] M. Romero-Gomez, M. Del Mar Viloria, R. J. Andrade et al., "Insulin resistance impairs sustained response rate to peginterferon plus ribavirin in chronic hepatitis C patients," Gastroenterology, vol. 128, no. 3, pp. 636-641, 2005.

[79] A. Alberti, "What are the comorbidities influencing the management of patients and the response to therapy in chronic hepatitis C?" Liver International, vol. 29, supplement 1, pp. 15-18, 2009.

[80] C. Hezode, E. S. Zafrani, F. Roudot-Thoraval et al., "Daily cannabis use: a novel risk factor of steatosis severity in patients with chronic hepatitis C," Gastroenterology, vol. 134, no. 2, pp. 432-439, 2008.

[81] G. Alvarez-Uria, J. N. Day, A. J. Nasir, S. K. Russell, and F. J. Vilar, "Factors associated with treatment failure of patients with psychiatric diseases and injecting drug users in the treatment of genotype 2 or 3 hepatitis C chronic infection," Liver International, vol. 29, no. 7, pp. 1051-1055, 2009.

[82] E. Lin, Y. Hwang, S. C. Wang, Z. J. Gu, and E. Y. Chen, "An artificial neural network approach to the drug efficacy of interferon treatments," Pharmacogenomics, vol. 7, no. 7, pp. 1017-1024, 2006.

[83] Y. Hwang, E. Y. Chen, Z. J. Gu et al., "Genetic predisposition of responsiveness to therapy for chronic hepatitis C," Pharmacogenomics, vol. 7, no. 5, pp. 697-709, 2006.

[84] Y. Huang, H. Yang, B. B. Borg et al., "A functional SNP of interferon-gamma gene is important for interferon-alpha induced and spontaneous recovery from hepatitis $\mathrm{C}$ virus infection," Proceedings of the National Academy of Sciences of the United States of America, vol. 104, no. 3, pp. 985-990, 2007.

[85] V. Suppiah, M. Moldovan, G. Ahlenstiel et al., "IL28B is associated with response to chronic hepatitis $\mathrm{C}$ interferonalpha and ribavirin therapy," Nature Genetics, vol. 41, no. 10, pp. 1100-1104, 2009.

[86] D. Ge, J. Fellay, A. J. Thompson et al., "Genetic variation in IL28B predicts hepatitis C treatment-induced viral clearance," Nature, vol. 461, no. 7262, pp. 399-401, 2009.

[87] Y. Tanaka, N. Nishida, M. Sugiyama et al., "Genome-wide association of IL28B with response to pegylated interferonalpha and ribavirin therapy for chronic hepatitis C," Nature Genetics, vol. 41, no. 10, pp. 1105-1109, 2009.

[88] A. Rauch, Z. Kutalik, P. Descombes et al., "Genetic variation in IL28B is associated with chronic hepatitis C and treatment failure: a genome-wide association study," Gastroenterology, vol. 138, no. 4, pp. 1338-1345, 2010.

[89] T. Kawaoka, C. N. Hayes, W. Ohishi et al., "Predictive value of the IL28B polymorphism on the effect of interferon therapy in chronic hepatitis $\mathrm{C}$ patients with genotypes $2 \mathrm{a}$ and $2 \mathrm{~b}$," Journal of Hepatology, vol. 54, no. 3, pp. 408-414, 2011.

[90] C. Sarrazin, S. Susser, A. Doehring et al., "Importance of IL28B gene polymorphisms in hepatitis $C$ virus genotype 2 and 3 infected patients," Journal of Hepatology, vol. 54, no. 3, pp. 415-421, 2011.

[91] U. P. Neumann, T. Berg, M. Bahra et al., "Long-term outcome of liver transplants for chronic hepatitis C: a 10-year followup," Transplantation, vol. 77, no. 2, pp. 226-231, 2004.
[92] L. M. Forman, J. D. Lewis, J. A. Berlin, H. I. Feldman, and M. R. Lucey, "The association between hepatitis C infection and survival after orthotopic liver transplantation," Gastroenterology, vol. 122, no. 4, pp. 889-896, 2002.

[93] D. K. Moonka, D. Kim, A. Kapke, K. A. Brown, and A. Yoshida, "The influence of induction therapy on graft and patient survival in patients with and without hepatitis $\mathrm{C}$ after liver transplantation," American Journal of Transplantation, vol. 10, no. 3, pp. 590-601, 2010.

[94] B. J. Veldt, J. J. Poterucha, K. D. Watt et al., "Impact of pegylated interferon and ribavirin treatment on graft survival in liver transplant patients with recurrent hepatitis C infection," American Journal of Transplantation, vol. 8, no. 11, pp. 2426-2433, 2008.

[95] J. A. Carrion, M. Navasa, M. Garcia-Retortillo et al., "Efficacy of antiviral therapy on hepatitis $\mathrm{C}$ recurrence after liver transplantation: a randomized controlled study," Gastroenterology, vol. 132, no. 5, pp. 1746-1756, 2007.

[96] D. Eurich, S. Boas-Knoop, M. Ruehl et al., "Relationship between the interleukin-28b gene polymorphism and the histological severity of hepatitis $\mathrm{C}$ virus-induced graft inflammation and the response to antiviral therapy after liver transplantation," Liver Transplantation, vol. 17, no. 3, pp. 289-298, 2011.

[97] T. Fukuhara, A. Taketomi, T. Motomura et al., "Variants in IL28B in liver recipients and donors correlate with response to peg-interferon and ribavirin therapy for recurrent hepatitis C," Gastroenterology, vol. 139, no. 5, pp. 1577-1585, 2010.

[98] C. M. Lange, D. Moradpour, A. Doehring et al., "Impact of donor and recipient IL28B rs12979860 genotypes on hepatitis C virus liver graft reinfection," Journal of Hepatology, vol. 55, no. 2, pp. 322-327, 2011.

[99] M. Colonna, G. Borsellino, M. Falco, G. B. Ferrara, and J. L. Strominger, "HLA-C is the inhibitory ligand that determines dominant resistance to lysis by NK1- and NK2-specific natural killer cells," Proceedings of the National Academy of Sciences of the United States of America, vol. 90, no. 24, pp. 12000-12004, 1993.

[100] N. Wagtmann, S. Rajagopalan, C. C. Winter, M. Peruzzi, and E. O. Long, "Killer cell inhibitory receptors specific for HLA$\mathrm{C}$ and HLA-B identified by direct binding and by functional transfer," Immunity, vol. 3, no. 6, pp. 801-809, 1995.

[101] S. I. Khakoo, C. L. Thio, M. P. Martin et al., "HLA and NK cell inhibitory receptor genes in resolving hepatitis $\mathrm{C}$ virus infection," Science, vol. 305, no. 5685, pp. 872-874, 2004.

[102] S. Knapp, U. Warshow, D. Hegazy et al., "Consistent beneficial effects of killer cell immunoglobulin-like receptor 2DL3 and group 1 human leukocyte antigen- $\mathrm{C}$ following exposure to hepatitis C virus," Hepatology, vol. 51, no. 4, pp. 11681175, 2010.

[103] J. R. Vidal-Castineira, A. Lopez-Vazquez, R. Diaz-Pena et al., "Effect of killer immunoglobulin-like receptors in the response to combined treatment in patients with chronic hepatitis C virus infection," Journal of Virology, vol. 84, no. 1, pp. 475-481, 2009.

[104] G. Ahlenstiel, M. P. Martin, X. Gao, M. Carrington, and B. Rehermann, "Distinct KIR/HLA compound genotypes affect the kinetics of human antiviral natural killer cell responses," Journal of Clinical Investigation, vol. 118, no. 3, pp. 10171026, 2008.

[105] V. Suppiah, S. Gaudieri, N. Armstrong et al., "IL28B, HLA$\mathrm{C}$, and KIR variants additively predict response to therapy in chronic hepatitis $\mathrm{C}$ virus infection in a European Cohort: 
a cross-sectional study," PLoS Medicine, vol. 8, no. 9, Article ID e1001092, 2011.

[106] A. D. Luster, J. C. Unkeless, and J. V. Ravetch, "Gammainterferon transcriptionally regulates an early-response gene containing homology to platelet proteins," Nature, vol. 315, no. 6021, pp. 672-676, 1985.

[107] L. F. Neville, G. Mathiak, and O. Bagasra, "The immunobiology of interferon-gamma inducible protein $10 \mathrm{kD}$ (IP10): a novel, pleiotropic member of the C-X-C chemokine superfamily," Cytokine and Growth Factor Reviews, vol. 8, no. 3, pp. 207-219, 1997.

[108] D. D. Taub, T. J. Sayers, C. R. Carter, and J. R. Ortaldo, "Alpha and beta chemokines induce NK cell migration and enhance NK-mediated cytolysis," The Journal of Immunology, vol. 155, no. 8, pp. 3877-3888, 1995.

[109] D. D. Taub, A. R. Lloyd, K. Conlon et al., "Recombinant human interferon-inducible protein 10 is a chemoattractant for human monocytes and T lymphocytes and promotes $\mathrm{T}$ cell adhesion to endothelial cells," Journal of Experimental Medicine, vol. 177, no. 6, pp. 1809-1814, 1993.

[110] A. I. Romero, M. Lagging, J. Westin et al., "Interferon (IFN)gamma-inducible protein-10: association with histological results, viral kinetics, and outcome during treatment with pegylated IFN-alpha 2a and ribavirin for chronic hepatitis C virus infection," Journal of Infectious Diseases, vol. 194, no. 7, pp. 895-903, 2006.

[111] M. Lagging, A. I. Romero, J. Westin et al., "IP-10 predicts viral response and therapeutic outcome in difficult-to-treat patients with HCV genotype 1 infection," Hepatology, vol. 44, no. 6, pp. 1617-1625, 2006.

[112] G. Askarieh, A. Alsio, P. Pugnale et al., "Systemic and intrahepatic interferon-gamma-inducible protein $10 \mathrm{kDa}$ predicts the first-phase decline in hepatitis $\mathrm{C}$ virus RNA and overall viral response to therapy in chronic hepatitis C," Hepatology, vol. 51, no. 5, pp. 1523-1530, 2010.

[113] M. Lagging, G. Askarieh, F. Negro et al., "Response prediction in chronic hepatitis $\mathrm{C}$ by assessment of IP-10 and IL28Brelated single nucleotide polymorphisms," PLoS One, vol. 6, no. 2, Article ID e17232, 2011.

[114] G. Fattovich, L. Covolo, S. Bibert et al., "IL28B polymorphisms, IP-10 and viral load predict virological response to therapy in chronic hepatitis C," Alimentary Pharmacology \& Therapeutics, vol. 33, no. 10, pp. 1162-1172, 2011.

[115] G. L. Davis, R. Esteban-Mur, V. Rustgi et al., "Interferon alfa$2 \mathrm{~b}$ alone or in combination with ribavirin for the treatment of relapse of chronic hepatitis C. International Hepatitis Interventional Therapy Group," The New England Journal of Medicine, vol. 339, no. 21, pp. 1493-1499, 1998.

[116] J. G. McHutchison, S. C. Gordon, E. R. Schiff et al., "Interferon alfa-2b alone or in combination with ribavirin as initial treatment for chronic hepatitis C. Hepatitis Interventional Therapy Group," The New England Journal of Medicine, vol. 339, no. 21, pp. 1485-1492, 1998.

[117] J. G. McHutchison, G. T. Everson, S. C. Gordon et al., "Telaprevir with peginterferon and ribavirin for chronic HCV genotype 1 infection," The New England Journal of Medicine, vol. 360, no. 18, pp. 1827-1838, 2009.

[118] M. P. Manns, J. G. McHutchison, S. C. Gordon et al., "Peginterferon alfa- $2 b$ plus ribavirin compared with interferon alfa$2 \mathrm{~b}$ plus ribavirin for initial treatment of chronic hepatitis C: a randomised trial," The Lancet, vol. 358, no. 9286, pp. 958$965,2001$.

[119] C. Hézode, N. Forestier, G. Dusheiko et al., "Telaprevir and PEGinterferon with or without ribavirin for chronic HCV infection," The New England Journal of Medicine, vol. 360, no. 18, pp. 1839-1850, 2009.

[120] F. Suzuki, N. Akuta, Y. Suzuki et al., "Rapid loss of hepatitis $\mathrm{C}$ virus genotype $1 \mathrm{~b}$ from serum in patients receiving a triple treatment with telaprevir (MP-424), pegylated interferon and ribavirin for 12 weeks," Hepatology Research, vol. 39, no. 11, pp. 1056-1063, 2009.

[121] H. Nomura, H. Tanimoto, E. Kajiwara et al., "Factors contributing to ribavirin-induced anemia," Journal of Gastroenterology and Hepatology, vol. 19, no. 11, pp. 1312-1317, 2004.

[122] S. Takaki, A. Tsubota, T. Hosaka et al., "Factors contributing to ribavirin dose reduction due to anemia during interferon alfa2b and ribavirin combination therapy for chronic hepatitis C," Journal of Gastroenterology, vol. 39, no. 7, pp. 668-673, 2004.

[123] K. Lindahl, R. Schvarcz, A. Bruchfeld, and L. Ståhle, "Evidence that plasma concentration rather than dose per kilogram body weight predicts ribavirin-induced anemia," Journal of Viral Hepatitis, vol. 11, no. 1, pp. 84-87, 2004.

[124] H. van Vlierbergh, J. R. Delanghe, M. de Vos, and G. LerouxRoel, "Factors influencing ribavirin induced hemolysis," Journal of Hepatology, vol. 34, no. 6, pp. 911-916, 2001.

[125] S. Sumi, A. M. Marinaki, M. Arenas et al., "Genetic basis of inosine triphosphate pyrophosphohydrolase deficiency," Human Genetics, vol. 111, no. 4-5, pp. 360-367, 2002.

[126] J. Fellay, A. J. Thompson, D. Ge et al., "ITPA gene variants protect against anemia in patients treated for chronic hepatitis C," Nature, vol. 464, no. 7287, pp. 405-408, 2010.

[127] M. Shipkova, K. Lorenz, M. Oellerich, E. Wieland, and N. von Ahsen, "Measurement of erythrocyte inosine triphosphate pyrophosphohydrolase (ITPA) activity by HPLC and correlation of ITPA genotype-phenotype in a Caucasian population," Clinical Chemistry, vol. 52, no. 2, pp. 240-247, 2006.

[128] S. Atanasova, M. Shipkova, D. Svinarov et al., "Analysis of ITPA phenotype-genotype correlation in the Bulgarian population revealed a novel gene variant in exon 6," Therapeutic Drug Monitoring, vol. 29, no. 1, pp. 6-10, 2007.

[129] T. Maeda, S. Sumi, A. Ueta et al., "Genetic basis of inosine triphosphate pyrophosphohydrolase deficiency in the Japanese population," Molecular Genetics and Metabolism, vol. 85, no. 4, pp. 271-279, 2005.

[130] J. Bierau, M. Lindhout, and J. A. Bakker, "Pharmacogenetic significance of inosine triphosphatase," Pharmacogenomics, vol. 8, no. 9, pp. 1221-1228, 2007.

[131] G. Stocco, M. H. Cheok, K. R. Crews et al., "Genetic polymorphism of inosine triphosphate pyrophosphatase is a determinant of mercaptopurine metabolism and toxicity during treatment for acute lymphoblastic leukemia," Clinical Pharmacology and Therapeutics, vol. 85, no. 2, pp. 164-172, 2009.

[132] J. H. Fraser, H. Meyers, J. F. Henderson, L. W. Brox, and E. E. McCoy, "Individual variation in inosine triphosphate accumulation in human erythrocytes," Clinical Biochemistry, vol. 8, no. 6, pp. 353-364, 1975.

[133] A. J. Thompson, J. Fellay, K. Patel et al., "Variants in the ITPA gene protect against ribavirin-induced hemolytic anemia and decrease the need for ribavirin dose reduction," Gastroenterology, vol. 139, no. 4, pp. 1181-1189, 2010.

[134] A. J. Thompson, R. Santoro, V. Piazzolla et al., "Inosine triphosphatase genetic variants are protective against anemia during antiviral therapy for $\mathrm{HCV} 2 / 3$ but do not decrease dose 
reductions of RBV or increase SVR," Hepatology, vol. 53, no. 2, pp. 389-395, 2011.

[135] H. Ochi, T. Maekawa, H. Abe et al., "ITPA polymorphism affects ribavirin-induced anemia and outcomes of therapya genome-wide study of Japanese HCV virus patients," Gastroenterology, vol. 139, no. 4, pp. 1190-1197, 2010.

[136] N. Sakamoto, Y. Tanaka, M. Nakagawa et al., "ITPA gene variant protects against anemia induced by pegylated interferonalpha and ribavirin therapy for Japanese patients with chronic hepatitis C," Hepatology Research, vol. 40, no. 11, pp. 1063-1071, 2010.

[137] D. L. Thomas, C. L. Thio, M. P. Martin et al., "Genetic variation in IL28B and spontaneous clearance of hepatitis C virus," Nature, vol. 461, no. 7265, pp. 798-801, 2009.

[138] A. Mangia, R. Santoro, M. Piattelli et al., "IL-10 haplotypes as possible predictors of spontaneous clearance of $\mathrm{HCV}$ infection," Cytokine, vol. 25, no. 3, pp. 103-109, 2004.

[139] C. Ishida, Y. Ikebuchi, K. Okamoto, and Y. Murawaki, "Functional gene polymorphisms of interleukin-10 are associated with liver disease progression in Japanese patients with hepatitis C virus infection," Internal Medicine, vol. 50, no. 7, pp. 659-666, 2011.

[140] R. Zampino, D. Ingrosso, E. Durante-Mangoni et al., "Microsomal triglyceride transfer protein (MTP)-493G/T gene polymorphism contributes to fat liver accumulation in HCV genotype 3 infected patients," Journal of Viral Hepatitis, vol. 15, no. 10, pp. 740-746, 2008.

[141] L. Valenti, M. Rumi, E. Galmozzi et al., "Patatin-like phospholipase domain-containing 3 I148M polymorphism, steatosis, and liver damage in chronic hepatitis C," Hepatology, vol. 53, no. 3, pp. 791-799, 2011. 


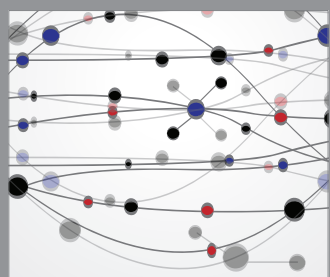

The Scientific World Journal
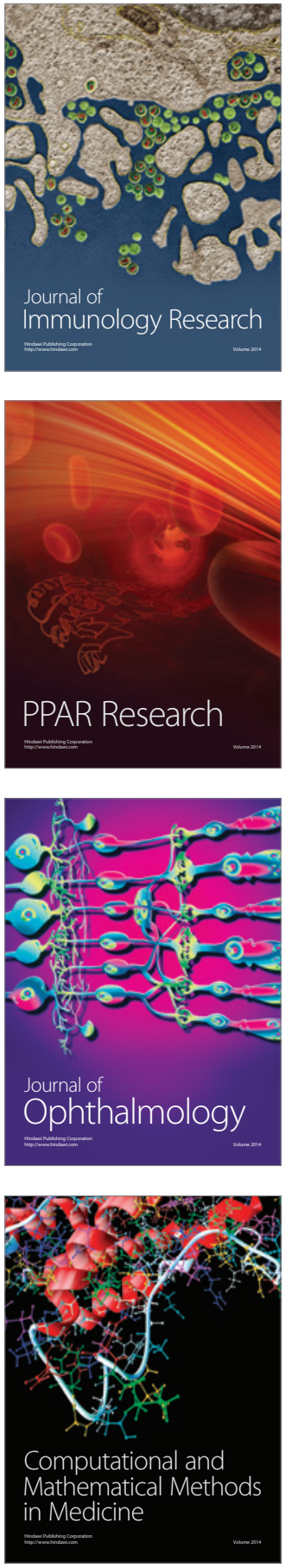

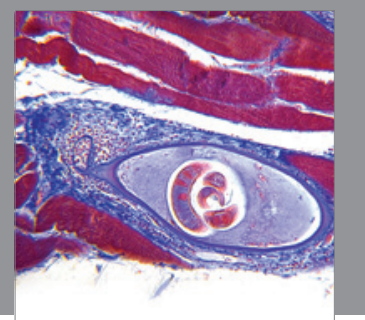

Gastroenterology

Research and Practice
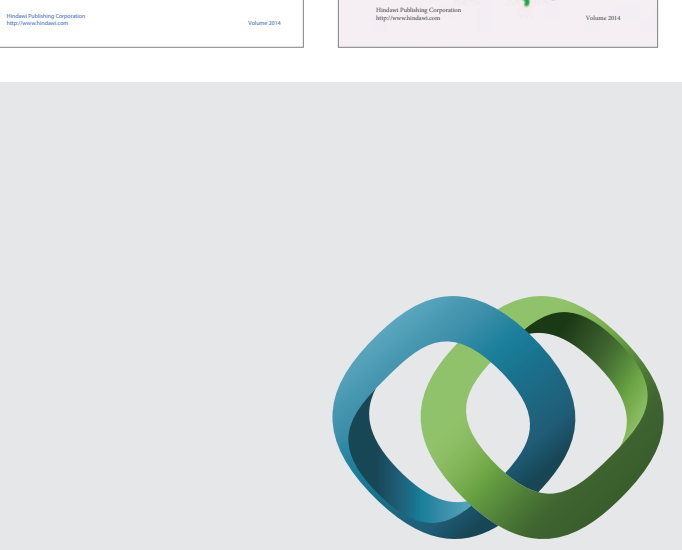

\section{Hindawi}

Submit your manuscripts at

http://www.hindawi.com
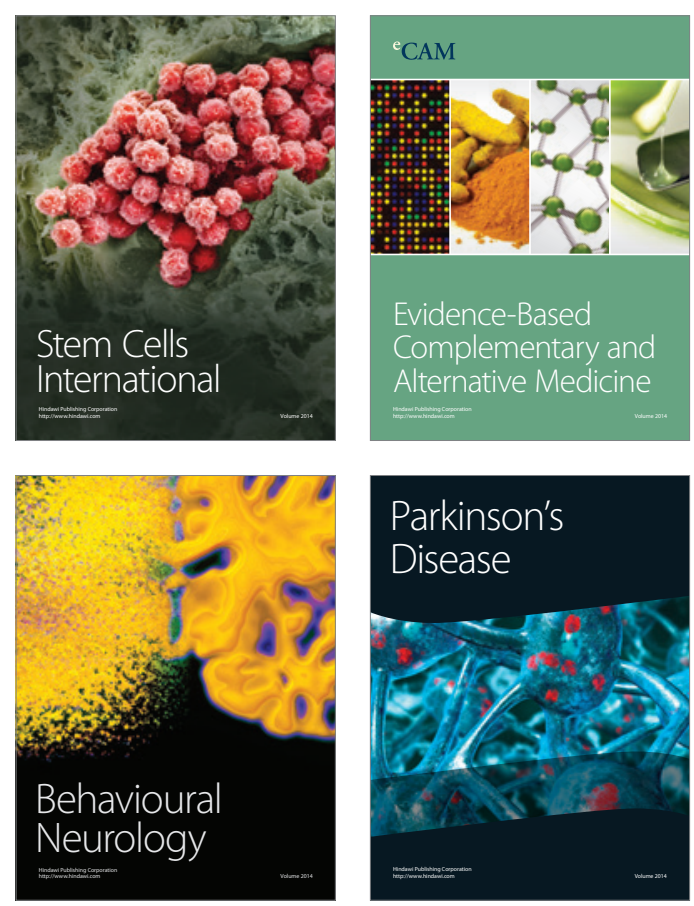

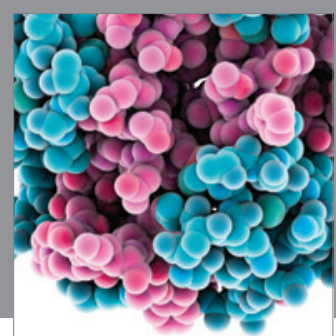

Journal of
Diabetes Research

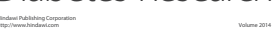

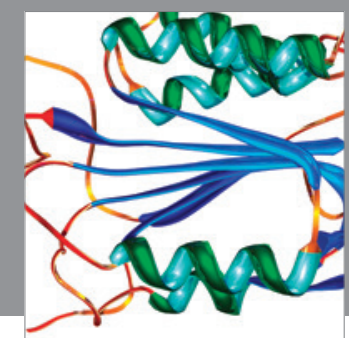

Disease Markers
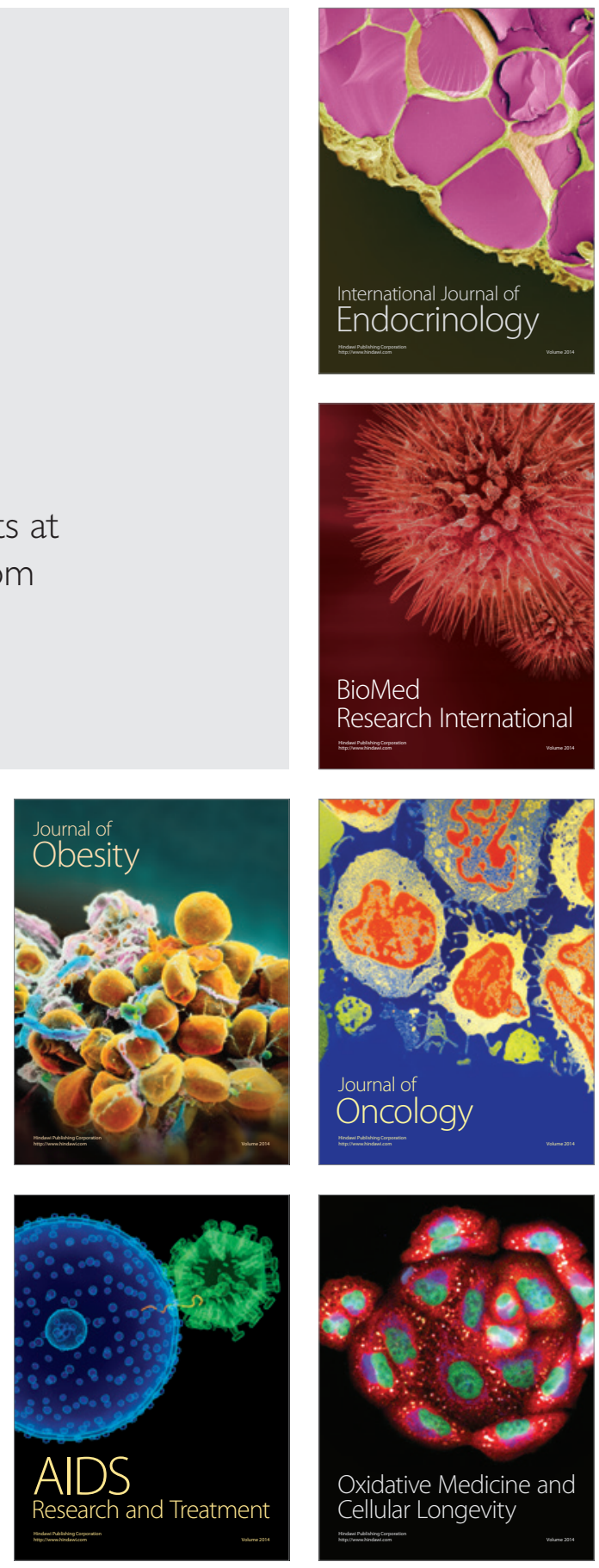